\title{
PERCEPCIÓN DEL PROCESO DE PLANIFICACIÓN ESTRATÉGICA COMO INSTRUMENTO DE LA POLÍTICA TURÍSTICAA ESCALA REGIONAL ${ }^{1}$
}

\author{
Ginesa Martínez del Vas \\ Universidad Católica de Murcia \\ gmvas@ucam.edu
}

\section{RESUMEN}

La planificación estratégica es un instrumento de la política turística que adquiere una gran relevancia a escala regional. En esta investigación se pretende conocer la percepción que tienen los diferentes agentes públicos y privados del proceso de planificación estratégica que se ha llevado a cabo, como instrumento de la política turística, en la Comunidad Autónoma de la Región de Murcia. Para ello, se ha utilizado el método Delphi como técnica de investigación cualitativa y se han seleccionado un conjunto de ítems que han permitido evaluar e identificar las cuestiones fundamentales y determinantes de los instrumentos de la política turística y, en mayor medida, de la planificación estratégica del turismo.

Palabras clave: Planificación estratégica, Región de Murcia, política turística, método Delphi.

\section{ABSTRACT}

Strategic planning is an instrument of tourism policy that has acquired great relevance on a regional scale. The purpose of this research aims to know the perception of both public and private stakeholders of the process of strategic planning that has been carried out, as an instrument of tourism policy, in the Region of Murcia. To this end, the Delphi technique has

Fecha de recepción: mayo 2016.

Fecha de aceptación: julio 2017.

1 El presente artículo recoge algunos de los aspectos tratados en la tesis doctoral de la autora sobre "La Planificación estratégica como instrumento de la política turística. Estudio aplicado a la Región de Murcia”, defendida en el Instituto Universitario de Investigaciones Turísticas de la Universidad de Alicante. 
been used as a qualitative research method. A set of items have been selected to evaluate and identify the fundamental and determinant issues of tourism policy instruments, and to a greater extent, tourism planning.

Keywords: Strategic planning, Region of Murcia, tourist policy, Delphi method.

\section{INTRODUCCIÓN}

El estudio de las políticas públicas por parte de los analistas ha estado centrado, primordialmente, en el análisis de las políticas orientadas al Estado del Bienestar. De esta forma, las políticas económicas, sociales, educativas, sanitarias, etc. se han convertido en los ejes de las investigaciones científicas, dejando en segundo término aquellas que tienen una relación menos directa con dichas políticas.

Dicho análisis comienza principalmente a mediados del siglo XX, debido a un evidente crecimiento de la intervención de los gobiernos en el desarrollo de este tipo de políticas, tal y como indica Velasco (2004). Comienza, entonces, el periodo donde se analiza y reflexiona sobre el funcionamiento de las políticas públicas y sus métodos, así como las técnicas utilizadas por los agentes decisorios, estableciendo una relación entre las necesidades, las acciones a llevar a cabo y los resultados obtenidos.

Cuando las políticas públicas intervienen en un área especializada y determinada se las denomina políticas sectoriales o macroáreas, como la política económica. En ellas, y como indica Bañón y Martínez, (2003: 238), el estado interviene "como empresa, como actor, como regulador y como planificador de la vida económica”.

Monfort (2000: 8) posiciona la actividad turística dentro de la política económica e indica que dicha política "contiene la aplicación de medidas, que juzgan oportunas los gobernantes, para alcanzar determinados objetivos”. Por su parte, Figuerola (1999: 203) define como concepto de política económica el "conjunto de acciones que persiguen adecuar los medios económicos o financieros a unos fines prioritarios. Estos fines tendrán una naturaleza muy diversa, que se extiende desde el crecimiento, a la mejora del uso de los bienes".

El campo de actuación de la política económica será tan amplio como sectores económicos existan y será el Estado el que determine los recursos económicos de que se dispone en cada sector. No obstante, siempre estarán determinadas varias variables. A saber: los intereses sociales, las consideraciones medioambientales o los beneficios directos e indirectos obtenidos. Pero cualquier acción u objetivo definido no debe, en ningún caso, establecer conflictos en el territorio que atenten contra los principios de la sostenibilidad. En el caso de la actividad turística, debido a sus características económicas, sociales, medioambientales, territoriales y culturales, es necesario que el Estado intervenga en la definición de una política específica que ordene y garantice una adecuada relación con las demás políticas públicas. Por consiguiente, se puede trasladar el concepto de política económica al caso concreto del turismo, estableciendo lo que este mismo autor (Figuerola, 1999: 203) determina como "política económica del turismo", esto es, "la necesidad de establecer acciones que puedan ser manejadas para conseguir objetivos prioritarios en la actividad turística”.

El turismo es una actividad que ha sido enfocada como un bien de consumo, producido por un sector económico definido y que es adquirido por el ciudadano. Por lo tanto, el mercado 
es responsable de su gestión y el Estado de corregir las posibles disfunciones que se puedan producir (Velasco, 2004). En consecuencia, existe una política turística que es considerada una política económica sectorial, que cuenta con el desarrollo de características asociadas a su principio de interdisciplinariedad como componente esencial de la propia actividad turística y, a su vez, cuenta con un profundo carácter económico. Así la política económica del turismo o política turística presenta objetivos concretos orientados en cada territorio de una forma diferente, basados en el nivel de influencia de la propia actividad sobre el espacio. En este sentido, las acciones de dicha política turística comienzan originariamente en la definición o reestructuración y equilibrio de los espacios o territorios, en las acciones de armonía de los propios flujos de visitantes en el entorno, en la protección de las estructuras turísticas que establecen puntos de presión, en los canales de promoción y en los aspectos legislativos.

El carácter multiplicador en la economía y su efecto e intervención trasversal en las restantes políticas es lo que convierte a la política turística en una política de intervención en el mercado. Por ello, se hace necesario garantizar las actuaciones que se llevan a cabo en materia turística, dada su enorme repercusión en el territorio.

En el caso de España la intervención en la política turística se encuentra unida al nacimiento de la actividad turística. Por ello, Vera y Marchena (1996: 347) nos hablan de la rapidez con la que se ha configurado la actividad turística española, que ha ocasionado que los profesionales y los propios políticos hayan tenido que ser "autodidactas". De igual modo, nos indican que "la política turística como tal, ha reconocido al turismo como un sector económico y social en sí mismo, de fuertes implicaciones en el empleo, el medio ambiente y la cultura en nuestro país, prácticamente no existiendo, aunque se recogiera como tal en los organismos políticos y administrativos.”. El desarrollo de la política turística, entonces, al igual que el resto de las políticas, ha sido objeto de una trasformación producida principalmente por los cambios del sistema político, la organización de la propia administración, la estructura económica y el mercado turístico, que han configurado lo que hoy se conoce como mercado turístico (Ivars, 2006). Sobre la política turística, como afirma Pulido (2004), no abunda la literatura científica, a pesar de ser básica para el estudio del turismo en su conjunto. Se tendrán en cuenta las aportaciones científicas de algunos autores, entre los que se destaca: Cals (1974), Hall y Jenkins (1995), Bote y Marchena (1996), Vera y Marchena (1996), Pedroño y Monfort (1996), López (1999), Bayón (1999), Monfort (2000), FayosSolá (2004), Velasco (2004, 2005, 2011 y 2016), Torres (2004), Pulido (2004), Figuerola (2004), Valdés (2004), López (2004), Ivars (2003 y 2007), Díaz (2007) Barroso y Flores (2007) y Bengochea (2009) entre otros.

Es necesario realizar un correcto análisis de la política turística como herramienta de conocimiento de las organizaciones administrativas públicas, con el fin de identificar los hechos y determinar las consecuencias de las acciones puestas en marcha en los determinados espacios administrativos. Es por ello que, dentro del marco teórico de esta investigación, se debe identificar la política turística suscrita en cualquier marco administrativo público, y especialmente en el autonómico, ya que este ámbito de actuación a escala regional es el nivel administrativo de intervención que cuenta con mayor poder de acción y mayor consenso con el resto de políticas sectoriales. De igual modo, no se debe considerar la política turística como un capítulo de la política económica, debido a que limita el análisis de esta acción política, aunque es necesario tener en consideración la perspectiva económica (Velasco, 2011). La política turística puede 
definirse, a partir de todo lo planteado, como las acciones que son llevadas a cabo por parte de la administración pública, definidas por el interés de desarrollar estrategias que se traducen en acciones y que responden a la intención de atraer y velar por la estancia de los turistas. Todo ello con el consenso de los distintos actores turísticos, tanto el sector privado como el de la propia sociedad local, y siempre atendiendo a las competencias territoriales del ámbito de actuación.

Bote y Marchena (1996: 297) proponen que en la política turística se debe distinguir entre fines y objetivos, tal y como se desarrollan en las propias políticas económicas. Así exponen que "el objetivo constituye una decisión sobre un problema de la actividad turística que se desea mejorar, a partir de un diagnóstico previamente definido”. Las metas las consideran como un objetivo cuantificable y los fines como opciones de desarrollo de un conjunto de objetivos. Asimismo, hablan de tipologías de objetivos y los clasifican en cuatro tipos: económicos, sociales, culturales y políticos. Queda patente que la intervención del Estado en el desarrollo de la actividad turística en el territorio tiene como principal función la de catalizador. Dicha intervención se lleva a cabo, entonces, mediante el estímulo, la promoción, la planificación, las garantías, la coordinación y la armonización de la propia acción turística en el territorio. Por lo tanto, es evidente que los objetivos de las políticas turísticas varían en relación con la fase en la que se encuentre el territorio respecto del desarrollo y del propio sistema turístico. Así, se establecerán los objetivos que tienen como finalidad el crecimiento de la actividad y los que están relacionados con la adaptación y mejora de la propia actividad.

En síntesis, cada objetivo seleccionado por la política sectorial turística deberá suponer una decisión operacional y una política instrumental. Esto es, y al margen de clasificaciones y tipologías diversas de los objetivos turísticos, estos estarán relacionados principalmente con el momento en el que se encuentre el proceso turístico, su trayectoria anterior y, lógicamente, su futuro más inmediato, que siempre responde a las decisiones de la propia política turística. Los objetivos de la política turística necesitan, entonces, de una serie de herramientas, que son las responsables de conseguir ejecutar las acciones propuestas. Los instrumentos deben estar adecuadamente planificados, quedando reflejado en cada uno de ellos su contenido, sus objetivos generales y específicos, y cuantificados los recursos materiales y humanos para poder llevar a cabo las acciones necesarias, sus fuentes de financiación y las fórmulas y actores que han de intervenir en su gestión (Bote y Marchena, 1996). En esta misma línea, Velasco (2004: 85) establece otra clasificación y habla de seis grupos de instrumentos: instrumentos organizativos, que agrupa en estructuras administrativas tradicionales, estructuras ejecutivas y estructuras de cooperación. En segundo lugar, se encuentran los instrumentos referentes a los Planes generales, definidos por la autora como "el instrumento básico que contiene el conjunto de acciones, cuyo fin es intervenir en el sector turístico en su totalidad". Los Programas conllevan la determinación de unos objetivos concretos con un alto grado de detalle y están dotados de los medios necesarios para su cumplimiento. En un cuarto lugar, los normativos, esto es, cualquier norma legal de aplicación directa sobre el sector turístico o la regulación de cualquiera de los componentes de la actividad turística. Los instrumentos financieros son el quinto de los instrumentos y, por último, lo constituyen las acciones de comunicación. De este modo, la Planes generales se configuran como el instrumento de planificación estratégica y adquieren una gran relevancia debido a que sus programas y estrategias identifican y ordenan las acciones que deben ser ejecutadas por los demás instrumentos de la política turística. 
Así la planificación estratégica siendo un concepto desarrollado en el ámbito empresarial ha adquirido un peso importante en los procesos de la gestión pública, debido al afán de establecer canales de gestión, que tuvieron en consideración la competitividad, el entorno y las necesidades sociales. La planificación estratégica pretende concebir un futuro deseable y establecer los medios reales para llegar al mismo, definiendo procesos orientados a la puesta en marcha de acciones bajo un proyecto integral, global y participativo que se estructura al amparo de unos objetivos concretos (Gómez, López, Cors, 2004). La planificación estratégica deriva al plan estratégico como documento que integra la reflexión sobre la acción futura, que según indica Antón y González (2005: 43) "es intentar prever el futuro para comprender algunas de las cosas que sucederán”. La estrategia es la acción resultante del plan en su conjunto, que nace de unos objetivos que arrojan un resultado triunfador. Es por ello, como se ha dicho anteriormente, que el plan de acción debe estar perfectamente diseñado para que dichos resultados obtengan los niveles más altos de competitividad. De este modo, entre los instrumentos de la política turística, es crucial analizar la importancia que la planificación estratégica tiene en el desarrollo de un destino turístico a escala regional y cómo es percibido desde los distintos agentes que intervienen en el mismo. Tras el análisis de las aportaciones llevadas a cabo por parte de la comunidad científica, entre los que se destaca: Sancho (1996), Velasco (2004, 2016), Vera et al. (1997, 2011), Vera y Marchena (1996) Acerenza (1985), Ivars (2003), Antón y González (2005), López (1999), Solsona (2010), Simancas (2016) entre otros, se observa un débil análisis que identifique el propio proceso de gestión y desarrollo del plan al margen de la elaboración y estructura del documento. Esto implica la necesidad de establecer mecanismos desde los que se atienda dicha gestión y que, consecuentemente, aporten veracidad al proceso de planificación. Previo a estas acciones deben desarrollarse dos ámbitos de gran relevancia: por un lado, la necesidad de establecer claras responsabilidades tanto en el contexto público como en el privado y, por otro, la de generar un claro compromiso social que respete los contenidos del documento. Este análisis conduce a entender la planificación estratégica tanto como una visión de futuro, como un proceso de análisis que sobre la base de unos objetivos consensuados entre los agentes público y privados, permita actuar sobre el territorio desde el compromiso de un crecimiento basado en los principios de la sostenibilidad.

\section{METOdOLOGÍA}

El marco de esta investigación pretende conocer la percepción por parte los distintos agentes públicos y privados sobre el proceso de planificación estratégica como instrumento de la política turística en la Comunidad Autónoma de la Región de Murcia.

Para tal propósito existe un amplio ámbito de métodos de investigación, que proporcionan información sobre pronósticos, aportando información sobre los escenarios futuros y analizando cuestiones que están sucediendo o han sucedido. Dentro de ese abanico de métodos, son los clasificados como "subjetivos" los que recogen las opiniones de personas o informantes, elegidas en función de su experiencia o conocimiento en temas de interés. Trabajar con información subjetiva no significa renunciar a la aplicación del método, ya que desarrollando estrategias que permitan recoger y analizar este tipo de información, de la forma más sistemática y efectiva posible, se puede alcanzar un mayor nivel de objetividad (Landeta, Matey, Ruiz y Villareal, 2002). 
En el presente estudio, se ha seleccionado una técnica de investigación cualitativa, que tradicionalmente se utiliza en las áreas de conocimiento de las ciencias sociales, concretamente, el método Delphi.

El método Delphi tiene su origen en los estudios realizados por Rand Corporation en Estados Unidos a finales de la década de los 40, aunque las primeras publicaciones acerca del método no llegaron hasta los años 60 (Dalkey y Helmer, 1963; Gordon y Helmer, 1964). Este fue desarrollado con el propósito de obtener una medida fiable del consenso entre un grupo de expertos, teniendo la ventaja de evitar una confrontación directa entre ellos (Okoli y Pawlowski, 2004). Por lo tanto, se trata de una técnica utilizada para desarrollar una opinión consensuada de un grupo de personas, reconocidas como "expertos, panelistas o informantes", guiados por una persona que coordina y modera el proceso. Aplicaciones posteriores han restado importancia a la obtención del consenso, siendo el objetivo primordial la obtención de información fiable acerca de las opiniones de los expertos (Landeta, 2006). Este método permite una comunicación estructurada entre el grupo, ofreciendo un feedback controlado acerca de las opiniones de los demás miembros.

Una de las utilidades más señaladas del método Delphi es la previsión de escenarios futuros en un campo determinado, habiéndose demostrado su validez en previsiones a corto, medio y largo plazo. Asimismo, se trata de una herramienta útil para la resolución de problemas complejos, para el desarrollo de marcos conceptuales en diferentes ámbitos y la identificación de aspectos clave o prioritarios (Okoli y Pawlowski, 2004). La flexibilidad del método es ampliamente reconocida, habiendo sido utilizado en numerosas disciplinas y campos de investigación en todo el mundo.

Son numerosas las aplicaciones del método Delphi en el campo de la investigación turística, habiendo proliferado durante las dos últimas décadas en diferentes países. Las primeras investigaciones estuvieron centradas en el campo de la previsión de tendencias futuras. Por ejemplo, Young et al. (1989) utilizaron un panel de 23 expertos para juzgar la probabilidad de ocurrencia y la importancia de 26 cuestiones acerca del turismo en Singapur. Kibedi (1981) informa de un estudio Delphi organizado durante un simposio de turismo internacional en 1979 donde se pidió a los participantes jerarquizar los eventos que ellos consideraban más influyentes en los negocios turísticos en los 80. Kaynak y Macaulay (1984) usaron el método Delphi para investigar la verosimilitud, el probable año de ocurrencia y la importancia de la industria del turismo en Nueva Escocia. Mouthino y Witt (1995) informan de los hallazgos de un Symposium Delphi en el que 25 expertos juzgaron la importancia y la probabilidad de ocurrencia de un número de posibles desarrollos futuros que afectarían al turismo mundial.

Más recientemente, los estudios Delphi estuvieron centrados en la identificación de factores influyentes o definitorios en diferentes áreas del turismo. Con este propósito, Miller (2001) aplicó un Delphi de dos rondas para la identificación de indicadores de turismo sostenible que podrían ayudar a los consumidores en la elección de sus vacaciones. El panel incluyo 74 expertos seleccionados por haber publicado acerca de turismo sostenible en reconocidas revistas del área. Los resultados mostraron un bajo grado de consenso en cuanto a la sostenibilidad, sin embargo, la estabilidad de las opiniones de la primera a la segunda ronda motivó la detención del proceso. También Tsaur, Lin y Lin (2006) trataron el tema de la sostenibilidad en el ecoturismo a través de la metodología Delphi en 
Taiwán. Basándose en una revisión de la literatura, seleccionaron 68 indicadores del ecoturismo que fueron valorados por un panel de doce expertos provenientes de diferentes áreas. También en Taiwán, Lee y King (2008) estudiaron los factores influyentes en el turismo de aguas termales, llegando al alcance de consenso tras la realización de tres rondas.

En España, son varios los estudios que han utilizado el método Delphi para la investigación turística. Landeta et al. (2002) aplicaron esta metodología para la estimación del gasto mínimo individual de los turistas que visitan Cataluña provenientes del resto de comunidades españolas en el ámbito de la producción de estadísticas de turismo. El uso del método Delphi vino justificado dada la dificultad para la obtención de la información acerca del gasto a través de encuestas telefónicas a la población. El panel utilizado incluyó 14 expertos provenientes de diferentes sectores turísticos (hostelero, restauración, apartamentos y campings, viajeros intensivos, etc.) los cuales participaron en el estudio Delphi compuesto por tres rondas. El consenso fue alcanzado en más del 50\% de los ítems y este fue superior al presentado en la primera ronda en todos los ítems. Basotti (2003) realizó un estudio Delphi con el objetivo de encontrar factores de calidad en el ecoturismo. El panel conto con 28 expertos a nivel internacional (16 países) de diferentes especialidades relacionadas con el ecoturismo (tour operadores, marketing, formadores, guías, consultores, etc.). Para el análisis de los resultados se utilizaron desviaciones típicas y el porcentaje de expertos que identificaron un factor como relevante. Otro importante estudio Delphi en España en el ámbito turístico, es el realizado por Pulido (2007) donde analizó los principales déficits de la política turística en los parques naturales andaluces. El panel fue constituido por un grupo de 17 expertos entre los que figuraban profesores universitarios, técnicos de las administraciones públicas andaluzas, miembros de instituciones públicas y privadas y profesionales. El cuestionario utilizado incluyó 386 ítems propuestos por los propios expertos donde se identificaron 289 déficits referentes a la gestión turística de los parques andaluces. Uno de los estudios españoles realizado más recientemente es el de Solsona-Monzonís y López-Olivares (2012) donde se investigaron factores influyentes en el turismo rural de la Comunidad Valenciana. Un panel de 21 expertos completó el estudio Delphi compuesto por dos rondas, identificando tanto factores con una incidencia positiva en el turismo rural, como posibles áreas de mejora.

Como se observa, el campo del turismo se ha beneficiado de la realización de estudios Delphi para la previsión, para la identificación de factores influyentes o para la definición de un área turística determinada. En este sentido, esta metodología se considera especialmente adecuada para la investigación en ciencias sociales, donde son numerosos los agentes implicados y la aportación grupal se considera más valiosa que la aportación individual.

\section{APLICACIÓN DEL MÉTODO AL ESTUDIO DE LA PLANIFICACIÓN ESTRÁTEGICA DEL TURISMO EN LA REGIÓN DE MURCIA}

\section{III.1. Planteamiento de la investigación y objetivos}

Son pocos los estudios realizados acerca de la planificación turística en la Región de Murcia. Estos han estado centrados en la descripción de las políticas, actuaciones y recursos 
de la Región de Murcia para el desarrollo del turismo cultural (Cabrían, 2004; 2005), el turismo rural (Millán 1999) o el turismo en el litoral y cultural (Andrés, 1998, 1999, 1999b, 2004; Andrés y Espejo, 2006, Vera y Espejo, 2006; García, Andrés, Espejo, 2016).

Estos trabajos constituyen valiosas aportaciones, sin embargo, no hay investigaciones empíricas recientes que aporten un nuevo conocimiento acerca de los instrumentos de la política turística, su importancia, su implantación y la previsión de escenarios futuros en el turismo de la región. Es por ello, que la presente investigación lleva a cabo un análisis sobre la definición y la importancia de la planificación estratégica como parte de la política turística en la Región de Murcia. En este marco se aplica el método Delphi al estudio de la planificación estratégica regional, estableciendo los siguientes objetivos:

- Conocer la valoración crítica sobre los instrumentos de la política turística en la Región de Murcia.

- Evaluar el grado de eficiencia de los planes turísticos como instrumento de la política turística en la Región de Murcia.

- Analizar los procesos clave de la planificación turística en la Región de Murcia.

- Identificar las cuestiones fundamentales y determinantes de la planificación turística regional, así como sus indicadores de seguimiento.

La elección del método Delphi para la consecución de estos objetivos viene justificada por la disponibilidad de un elevado número de expertos con la información y la intuición necesarias para la aportación del conocimiento en este campo. Por otro lado, el desarrollo actual de las tecnologías de la información permite superar dos limitaciones de esta metodología, el coste de tiempo y la adherencia de los expertos al estudio, ya que permiten acelerar y simplificar el proceso de intercambio de información (Landeta et al., 2002).

\section{III.2. La selección de los expertos y elaboración del cuestionario}

El criterio básico para la selección de los panelistas fue su consideración de expertos por sus conocimientos y su alta cualificación en el sector turístico regional y que, por lo tanto, pudieran aportar información relevante a la investigación.

Asimismo, se intentó que el panel estuviera compuesto tanto por representantes del sector público (cargos de la administración pública, técnicos públicos, etc.) como privado (empresariado privado reconocido, representantes del sector hostelero, etc.) del turismo en la Región de Murcia. De esta forma fueron seleccionados e invitados a participar 17 expertos, número suficiente, dadas las características del estudio y las recomendaciones metodológicas del Delphi (Delbeq et al., 1975).

Cada uno de los expertos fue contactado telefónicamente a excepción de uno de ellos, que lo fue vía email. Al contactar con ellos, se les aportó la siguiente información, siguiendo lo especificado por Landeta (1999: 63):

- Información sobre los objetivos de la investigación.

- Naturaleza y características de la metodología utilizada.

- Tipología de candidatos y criterios que se han escogido para su selección. 
- Número de cuestionarios que se habrán de cumplimentar y tiempo aproximado a destinar a cada uno.

- Duración aproximada del proceso que será en torno a unos 5 meses

- Procesos del uso de la información recibida

- Beneficios objetivos que conseguirán con su participación.

Todos los panelistas participaron de forma voluntaria en el estudio y sin remuneración alguna. En la Tabla 1 se puede apreciar la composición final del panel de acuerdo al sector turístico y al cargo ocupado por los expertos.

Tabla 1

COMPOSICIÓN DEL PANEL SEGÚN LA PROCEDENCIA DE LOS EXPERTOS

\begin{tabular}{llc}
\hline Sector & Cargo que ocupa u ocupó & Número \\
\hline Administración pública & $\begin{array}{l}\text { Director General de Turismo } \\
\text { Responsable de empresa pública de turismo } \\
\text { Técnicos de turismos } \\
\text { Profesor de Universidad }\end{array}$ & 6 \\
\hline $\begin{array}{l}\text { Organizaciones y empresas } \\
\text { del sector privado. }\end{array}$ & $\begin{array}{l}\text { Directores de Hoteles } \\
\text { Representante del sector privado en asociaciones } \\
\text { Personas destacadas como empresarios } \\
\text { Representantes-coordinadores de producto turístico }\end{array}$ & 11 \\
\hline
\end{tabular}

Fuente: elaboración propia.

El diseño del cuestionario parte, por un lado, de la revisión y descripción realizada acerca de los instrumentos y planes turísticos y, por otro, de la revisión de la literatura (Beas, 2009, 2012; López-Palomeque, 2004; López Olivares, Antón, Navarro, Perelli y Sastre, 2005 Pulido, 2007a; 2007b). Asimismo, se han tenido en cuenta los objetivos de la investigación, quedando el cuestionario dividido en 11 bloques distribuidos en 4 áreas que se corresponden con cada uno de los objetivos de la investigación, incluyéndose un total de 134 ítems. La estructura del cuestionario se resume en la Tabla 2.

El cuestionario cuenta con una introducción previa que expresa a los sujetos la intención del proceso y el valor de su opinión para la investigación. La estructura de las preguntas ha sido clara y concisa, siempre se ha intentado que sean correctamente entendidas y que no condicionen las respuestas. Los 134 ítems fueron elaborados de forma que permitieran un análisis estadístico de las respuestas, lo que se consideró necesario tanto a efectos de integración cuantitativa de la información, como por el elevado número de ítems a responder. En este sentido, se solicitó a los expertos que en función del criterio indicado (importancia, satisfacción, conocimiento, adaptación, influencia y ejecución) emitieran juicios de valoración de acuerdo a una escala Likert de 1 a 7 puntos, donde 1 es el valor mínimo y 7 es el valor máximo.

Además, tras finalizar cada bloque de preguntas cerradas, se incluyeron dos apartados de respuesta abierta; el primero de ellos, otros aspectos no indicados, con el objetivo de 
que los expertos pudieran hacer propuestas acerca de cuestiones no contempladas en el cuestionario y que pudieran resultar relevantes para el tema de estudio. El segundo apartado fue referente a observaciones, donde los expertos podrían añadir cuestiones, aclaraciones o cualquier otro tipo de información adicional. De esta forma también se recogió información de tipo cualitativo.

Tabla 2

ESTRUCTURA DEL CUESTIONARIO

\begin{tabular}{l}
\hline ÁREA 1. Valoración crítica de los instrumentos de la política turística en la Región 47 ítems \\
de Murcia.
\end{tabular}

Bloque 1.1. Importancia de los instrumentos de la política turística

Bloque 1.2. Satisfacción con los instrumentos de la política turística

Bloque 1.3. Importancia de la planificación turística

ÁREA 2. Evaluación de la eficiencia de los planes turísticos como instrumento de la 20 ítems
política turística en la Región de Murcia

Bloque 2.1. Grado de conocimiento de los planes turísticos

Bloque 2.2. Grado de adaptación de los planes turísticos

Bloque 2.3. Grado de influencia positiva de los planes turísticos

Bloque 2.4. Grado de ejecución de los planes turísticos

ÁREA 3. Evaluación de los procesos clave de la planificación turística en la Región 35 ítems
de Murcia.

Bloque 3.1. Aspectos positivos del escenario turístico

Bloque 3.2. Aspectos positivos de los actores turísticos

Bloque 3.3. Aspectos negativos del escenario turístico

Bloque 3.4. Aspectos negativos de los actores turísticos

\begin{tabular}{l}
\hline ÁREA 4. Análisis de las cuestiones fundamentales de la planificación turística e 32 ítems \\
identificación de determinantes para su adecuación en la Región de Murcia.
\end{tabular}

Bloque 4.1. Cuestiones fundamentales de la planificación turística (escenario

turístico)

Bloque 4.2. Cuestiones fundamentales de la planificación turística (actores turísticos)

Bloque 4.3. Indicadores genéricos de la implantación de la planificación turística

Fuente: elaboración propia.

\section{III.2.1. Primera ronda: recogida y análisis de la información}

Tras conocer la conformidad de los expertos para su colaboración en la investigación, se les hizo llegar el cuestionario, por correo electrónico, donde también se explicó todo el proceso. Se estableció un tiempo limitado de dos semanas para el envío de las respuestas (del 1 de marzo al 18 de marzo del 2013). La mayoría de los expertos enviaron sus cuestionarios dentro del periodo establecido; fueron pocos los que lo hicieron en días posteriores.

Recibidas las respuestas se obtuvieron los estadísticos descriptivos que aportarían valores numéricos calculados a partir de la muestra y que, de este modo, resumieran la información contenida en ella. 
Se seleccionó la Media Aritmética como indicador de centralización que indica el promedio de las observaciones, es decir, el cociente entre la suma de todos los datos y el número total de ellos. Asimismo, se obtuvo la Desviación Típica como indicador de dispersión que indica la mayor o menor concentración de los datos con respecto a las medidas de centralización, que, en este caso, es la media. Estos estadísticos descriptivos fueron ofrecidos como feedback de los resultados a los expertos junto al envío del cuestionario en la segunda ronda.

\section{III.2.2. Segunda ronda: recogida y análisis de la información}

Obtenidos estos datos se rediseña el cuestionario aportando a cada informante o experto el análisis cuantitativo obtenido para cada ítem, la media, la desviación típica y su respuesta en la primera oleada u ronda, indicándole si quiere modificar su respuesta hacia la media. El cuestionario facilitado a cada uno de los expertos no presentó variaciones con respecto al administrado en la primera ronda. Igualmente, este se hizo llegar mediante correo electrónico y se concedieron dos semanas para obtener las respuestas definitivas (del 10 al 27 de mayo de 2013).

Tras la recepción de las respuestas se procedió al análisis de estabilidad de las mismas para valorar la conveniencia de la detención del proceso de rondas. Dada la presencia de estabilidad en las respuestas de los expertos se dio por finalizado el proceso y se procedió a la elaboración de los resultados.

\section{III.2.3. Elaboración de resultados}

La información recogida a través de la metodología Delphi permite un análisis tanto cuantitativo como cualitativo. En cuanto al análisis cuantitativo de los resultados, como se ha comentado, se calculó tras finalizar la segunda ronda. El cambio en el coeficiente de variación para comprobar la conveniencia de la detención del proceso de oleadas a través de la aplicación del criterio de estabilidad. En segundo lugar, se llevó a cabo un análisis descriptivo de las respuestas de los expertos mediante la obtención de los estadísticos de tendencia central, media y mediana y los índices de dispersión, mínimo y máximo (rango) y desviación típica. Las medias y desviaciones típicas también fueron calculadas en la primera ronda ya que estas fueron aportadas como feedback a los expertos tras la finalización de la misma. En tercer lugar, el consenso fue analizado atendiendo a las distribuciones porcentuales de las respuestas de expertos en los diferentes valores de la escala y al coeficiente de variación. Por último, se llevaron a cabo pruebas de significación T de Student para medias independientes con el objetivo de comparar las opiniones del sector, publico vs. privado en cada uno de los ítems. Los diferentes estadísticos se presentan bien de forma numérica o bien gráficamente. Los programas de software utilizados para la realización de los análisis estadísticos fueron Microsoft Excel 2007 e IBM SPSS 21.

Por otro lado, el análisis cualitativo de los resultados consistió en la descripción de las repuestas de los expertos a los ítems de repuesta abierta, analizando la coincidencia de ideas y las líneas de opinión en función de la procedencia de los expertos. 
La Tabla 3 muestra las principales características del presente estudio, mientras que en la Figura 1 se puede ver un resumen de todo el proceso seguido para el desarrollo del método Delphi en la presente investigación.

Tabla 3

FICHA TÉCNICA DEL MÉTODO DELPHI

\begin{tabular}{ll}
\hline Ámbito de estudio & $\begin{array}{l}\text { Expertos regionales en turismo y conocedores de los procesos de } \\
\text { planificación estratégica del turismo regional. }\end{array}$ \\
\hline Tamaño de la muestra & $\begin{array}{l}17 \text { cuestionarios en la primera ronda } \\
17 \text { cuestionarios en la segunda roda }\end{array}$ \\
\hline Fecha del trabajo & $\begin{array}{l}\text { Inicio: } 1 \text { de marzo de } 2013 \\
\text { Fin: } 13 \text { de junio de } 2013\end{array}$ \\
\hline Número de ítems & 134 \\
\hline
\end{tabular}

Fuente: elaboración propia.

Figura 1

DESARROLLO DEL MÉTODO DELPHI EN LA PRESENTE INVESTIGACIÓN

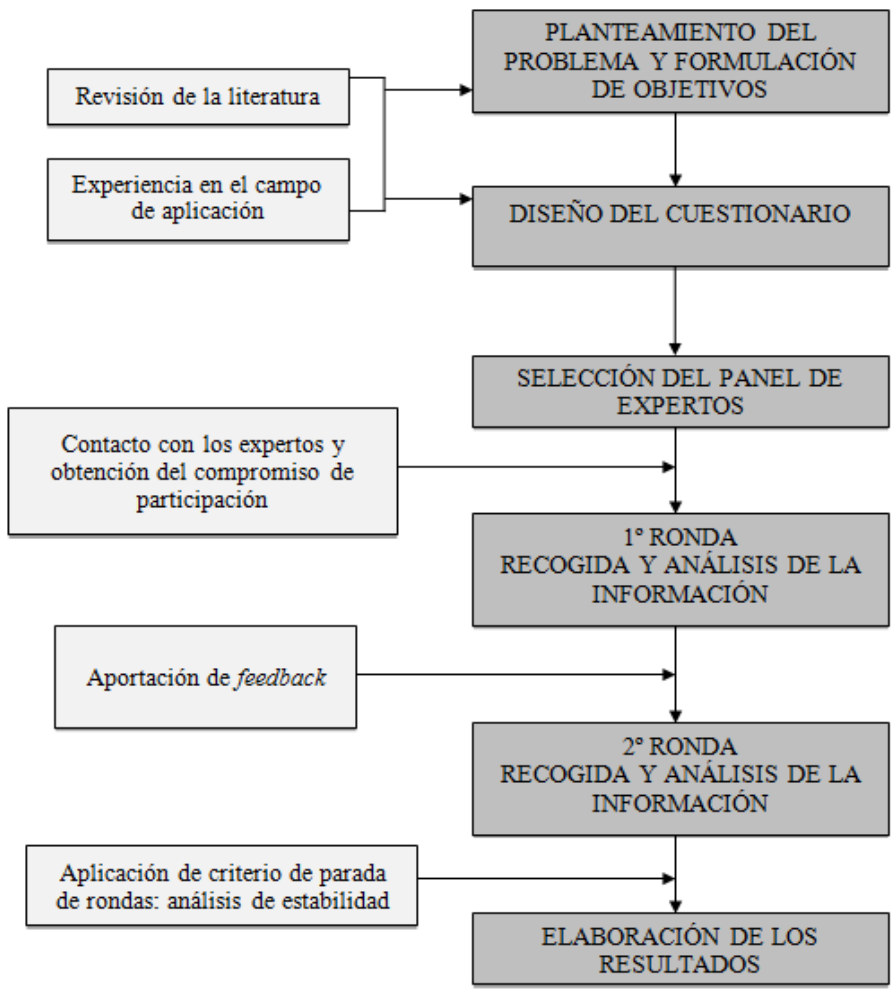

Fuente: elaboración propia. 


\section{III.2.4. Criterio de Parada: análisis de la estabilidad}

El método Delphi requiere el establecimiento de criterios para la detención del proceso de oleadas o rondas, ya que se ha comprobado que con un número reducido de rondas se suele alcanzar un grado de consenso prácticamente estático (Gordon y Helmer, 1964), independientemente de si este es alto o bajo. Es por ello que se hace necesario el uso de criterios de parada para no llevar a cabo rondas innecesarias o que provoquen el alcance de un falso consenso.

Tradicionalmente el criterio utilizado ha sido el grado de consenso, es decir, el proceso se detenía cuando las opiniones alcanzaban un grado aceptable de proximidad. Sin embargo, se han observado ciertas desventajas con la utilización de este criterio. Por un lado, realizar sucesivas rondas hasta obtener el consenso deseado tiene el peligro de forzar en exceso a los encuestados hacia la convergencia y por otro, se pueden ignorar corrientes subgrupales de opinión contraria, lo que supone una pérdida de información (Landeta, 1999).

Dadas las inconveniencias derivadas del uso del criterio clásico, en el presente estudio se ha optado por el empleo del criterio de estabilidad para determinar la parada de las oleadas, más recomendado en la actualidad (Rowe y Wright, 2001). Se considera la existencia de estabilidad cuando no se produce una variación significativa en las opiniones de los expertos entre rondas sucesivas, independientemente del grado de consenso alcanzado (Landeta, 1999). Utilizando este criterio es posible obtener información más acorde con la realidad y evitar forzar un falso consenso.

Son varias las técnicas estadísticas que se pueden utilizar para medir la estabilidad. En el presente estudio se ha llevado a cabo el análisis del cambio en el coeficiente de variación (CCV), un método basado en la estabilidad grupal, es decir, la variabilidad no significativa de las opiniones entre los miembros del grupo de la primera ronda a la segunda ronda. Este índice es uno de los estadísticos de primera elección de acuerdo a la literatura acerca del método Delphi (Landeta, 1999).

El coeficiente de variación (CV) es un índice estadístico de dispersión especialmente indicado cuando se quieren comparar niveles de variabilidad en diferentes grupos o momentos de evaluación (en este caso la variabilidad entre la Ronda 1 y la Ronda 2). Se calcula dividiendo la desviación típica $(S)$ entre la media (), tal y como aparece en la ecuación:

$$
C V=\frac{S}{\bar{X}}
$$

Para el análisis del cambio en la variabilidad se calculó la diferencia entre el coeficiente de variación de la primera ronda y el obtenido en la segunda ronda para cada uno de los ítems del cuestionario $\left(\mathrm{CCV}=\mathrm{CV}_{1-} \mathrm{CV}_{2}\right)$. Se consideró la existencia de estabilidad cuando la diferencia entre ambos coeficientes se situó entre \pm 0.10 . Este valor criterio fue definido de forma arbitraria de acuerdo a las características del estudio, tal y como se aconseja en la literatura acerca del método Delphi cuando se usa este coeficiente (Landeta, 1999; Ortega, 2008).

En cuanto a los resultados derivados de este análisis, todas las preguntas que componen el cuestionario cumplen el criterio establecido, a excepción de algunas cuestiones del Bloque 2 del Área 1: Valoración crítica de los instrumentos de la política turística en la Región de 
Murcia. En este bloque (Instrumentos de la política turística (satisfacción) cuatro de sus ítems superan el valor de 0.10: el 2.1. Fórmulas de organización (consorcios, etc.) con un valor de $\mathrm{CCV}=0.11$; el 2.3. Planes de excelencia, dinamización y producto con $\mathrm{CCV}=0.12$; el 2.8. Gestión de la marca turística regional con CCV=0.13; y el 2.11. Campañas de publicidad con un $\mathrm{CCV}=0.15$. Por lo tanto, el Bloque 2 del Área 1 es el que menos estabilidad presenta del cuestionario. El que la variabilidad de los ítems de satisfacción mostrase cambios de una ronda a otra podría ser debido a la subjetividad del constructo de satisfacción, lo que pudo hacer más efectivo el feedback para que los expertos modificasen sus respuestas de una ronda a otra en mayor medida que cuando expresaron su opinión acerca de aspectos más objetivos, como la ejecución o el conocimiento, entre otros.

A pesar de percibirse cambios en la variabilidad de los mencionados ítems de la primera a la segunda ronda, se consideró que esta proporción de ítems como no relevante en relación al conjunto total de 134 ítems, por lo que la detención del proceso, en la segunda ronda, queda justificada de acuerdo al criterio de estabilidad.

\section{SÍNTESIS DE LOS PRINCIPALES RESULTADOS OBTENIDOS}

\section{IV.1. Resultados del análisis de la situación}

A continuación, se presentan resumidamente los ítems con mayor y menor consenso de cada área. Para su ordenación, se ha utilizado el CV, dada la dificultad de establecer consenso a través de los porcentajes, debido a la amplitud del rango de respuestas (de 1 a 7) y a la heterogeneidad de los datos, aspecto anteriormente comentado.

En la valoración del Área 1. Valoración crítica de los instrumentos de la política turística en la Región de Murcia, todos los instrumentos de la política turística son considerados importantes para el desarrollo de la planificación en la Región de Murcia, sin embargo, el funcionamiento de los mismos es considerado como poco satisfactorio para los expertos. El ítem con mayor consenso en el grado de importancia es el que corresponde a la formación, pero el instrumento valorado como más importante ha sido la gestión de la marca turística y el menos valorado acciones de fidelización. Respecto del grado de satisfacción, los instrumentos valorados como más satisfactorios fueron las acciones de innovación y como el menos satisfactorio la gestión de la marca, siendo para los expertos el aspecto más importante. El mayor consenso se observa en la información al turista y el menor en las acciones de fidelización, al igual que en el grado de importancia (ver tabla 4)

En cuanto a la valoración de la importancia de la planificación turística regional, los expertos le han otorgado una importancia elevada en términos generales. Los motivos más valorados son por ser una herramienta necesaria para el desarrollo del turismo regional por su carácter integrador y un documento de argumentación que ordena las decisiones de la política turística. El más consensuado por su importancia es un instrumento que ordena al resto de instrumentos de la política turística. Donde se observa menos consenso es por ser un documento de argumentación que justifica las decisiones de la política turística. Los expertos consideran que es importante ordenar las decisiones, pero el documento no debe justificar sus acciones. 
Como conclusión del análisis se puede decir que la gestión de la marca es uno de los instrumentos más importantes de la política turística y donde los expertos se encuentran menos satisfechos. Están de acuerdo en que las acciones de innovación e información al turista son instrumentos que se gestionan adecuadamente. Respecto de la planificación estratégica regional, la consideran importante para la Región de Murcia, especialmente por ser una herramienta necesaria para el desarrollo del turismo regional, por su carácter integrador y por su importancia como instrumento que ordena las decisiones y el resto de instrumentos de la política turística.

Tabla 4

ITTEMS CON MAYOR Y MENOR CONSENSO DEL ÁREA 1. VALORACIÓN CRÍTICA DE LOS INSTRUMENTOS DE LA POLITICA TURISTICA EN LA REGIÓN DE MURCIA

\begin{tabular}{l|l|l|c}
\hline AREA 1. Valoración crítica de los instrumentos de la política turística en la Región de Murcia \\
\hline Ítem & Mediana & $\begin{array}{l}\text { Valor con } \\
\text { mayor \% }\end{array}$ & CV \\
\hline
\end{tabular}

Ítem mayor consenso Bloque 1.1 Grado de importancia de los instrumentos de la política turística para el desarrollo de la Región de Murcia.

\begin{tabular}{l|l|l|l}
\hline Formación (1.4) & 6 & $6(65 \%)$ & 0.09 \\
\hline
\end{tabular}

Ítem mayor consenso bloque 1.2. Grado de satisfacción de los instrumentos de la política turística para el desarrollo de la Región de Murcia.

\begin{tabular}{l|c|c|c}
\hline Información al turista (2.17) & 5 & $5(41 \%)$ & 0.24 \\
\hline $\begin{array}{l}\text { Ítem mayor consenso Bloque 1.3. Grado de importancia del Plan turístico de la Región de } \\
\text { Murcia }\end{array}$ \\
$\begin{array}{l}\text { Por su importancia es un instrumento que ordena al resto de } \\
\text { instrumentos de la política turística (3.1) }\end{array}$ & 6 & $6(47 \%)$ & 0.29 \\
\hline
\end{tabular}

Ítem menor consenso Bloque 1.1 Grado de importancia de los instrumentos de la política turística para el desarrollo de la Región de Murcia.

\begin{tabular}{l|l|l|l}
\hline Acciones de fidelización (1.12) & 5 & $5(41 \%)$ & 0.34 \\
\hline
\end{tabular}

Ítem menor consenso Bloque 1.2 Grado de satisfacción de los instrumentos de la política turística para el desarrollo de la Región de Murcia.

\begin{tabular}{l|c|c|c}
\hline Acciones de fidelización (2.12) & 2 & $2(41 \%)$ & 0.56 \\
\hline $\begin{array}{l}\text { Ítem menor consenso Bloque 1.3. Grado de importancia del Plan turístico de la Región de } \\
\text { Murcia }\end{array}$ \\
$\begin{array}{l}\text { Un documento de argumentación que justifica las decisiones de la } \\
\text { política turística (3.3) }\end{array}$ & 5 & $\begin{array}{r}4(24 \%) \\
6(24 \%)\end{array}$ & 0.37 \\
\hline
\end{tabular}

Fuente: elaboración propia.

En cuanto al análisis del Área 2: Evaluación de la eficiencia de los planes turísticos como instrumento de la política turística en la Región de Murcia, se ha observado que los planes turísticos con más tiempo en el escenario turístico regional tuvieron una valoración más elevada en general por parte de los expertos que aquellos que llevan menos tiempo. Cabe destacar, sin embargo, que estos fueron valorados en general con valores medios-bajos en todas las áreas. 
Tabla 5

ITEMS CON MAYOR Y MENOR CONSENSO DEL ÁREA 2. EVALUACIÓN DE LA EFICIENCIA DE LOS PLANES TURISTICOS COMO INSTRUMENTO DE LA POLITICA TURISTICA EN LA REGIÓN DE MURCIA

ÁREA 2. Evaluación de la eficiencia de los planes turísticos como instrumento de la política turística en la Región de Murcia

\begin{tabular}{l|l|l|l}
\hline Ítem & Mediana & $\begin{array}{l}\text { Valor con } \\
\text { mayor \% }\end{array}$ & CV \\
\hline
\end{tabular}

Ítem mayor consenso Bloque 2.1. Grado de conocimiento del sector turístico de la Región de Murcia

\begin{tabular}{|l|l|l|l}
\hline Plan Director del turismo de la Región de Murcia 2010-2015 (4.3) & 4 & $4(35 \%)$ & 0.42 \\
\hline
\end{tabular}

Ítem mayor consenso Bloque 2.2. Grado de adaptación de los Planes a los principios de planificación regional.

\begin{tabular}{l|l|l|l}
\hline Plan de Fomento del turismo de la Región de Murcia (5.2) & 4 & $6(18 \%)$ & 0.40 \\
\hline
\end{tabular}

Ítem mayor consenso Bloque 2.3. Grado de influencia de los Planes en la política turística de la Región de Murcia.

\begin{tabular}{|l|l|l|l}
\hline Plan de Fomento del turismo de la Región de Murcia (6.2) & 5 & $6(24 \%)$ & 0.40 \\
\hline
\end{tabular}

Ítem mayor consenso Bloque 2.4. Grado de ejecución de los Planes en el escenario turístico de la Región de Murcia

\begin{tabular}{|l|l|l|l}
\hline Plan de Fomento del turismo de la Región de Murcia (7.2) & 5 & $5(18 \%)$ & 0.46 \\
\hline
\end{tabular}

Ítem menor consenso Bloque 2.1. Grado de conocimiento del sector turístico de la Región de Murcia

\begin{tabular}{l|c|c|c}
\hline Plan de Desarrollo del turismo de la Región de Murcia (4.1) & 3 & $3(35 \%)$ & 0.49 \\
\hline Estrategia de Innovación para el sector empresarial turístico (4.5) & 3 & $\begin{array}{r}3(24 \%) \\
4(24 \%)\end{array}$ & 0.49 \\
\hline
\end{tabular}

Ítem menor consenso Bloque 2.2. Grado de adaptación de los Planes a los principios de planificación regional.

\begin{tabular}{l|l|l|l|l}
\hline Estrategia de Innovación para el sector empresarial turístico (5.5) & 4 & $3(18 \%)$ & 0.48 \\
\hline
\end{tabular}

Ítem menor consenso Bloque 2.3. Grado de influencia de los Planes en la política turística de la Región de Murcia.

\begin{tabular}{|l|l|l|l}
\hline Plan de Desarrollo del turismo de la Región de Murcia (6.1) & 3 & $3(24 \%)$ & 0.54 \\
\hline
\end{tabular}

Ítem menor consenso Bloque 2.4. Grado de ejecución de los Planes en el escenario turístico de la Región de Murcia

\begin{tabular}{l|l|l|l|l}
\hline Estrategias de desarrollo del turismo de la Región de Murcia (7.4) & 2 & $2(18 \%)$ & 0.52 \\
\hline
\end{tabular}

Elaboración propia.

En este sentido, las Estrategias de desarrollo Turístico de la Región de Murcia 20102015 es un documento poco conocido, que no se adapta adecuadamente a los principios de la planificación regional y que ejerce poca influencia positiva, según las opiniones de los expertos. Por el contrario, el Plan de Fomento del turismo de la Región de Murcia y Plan Director del Turismo de la Región de Murcia 2006-2012 son conocidos en mayor medida y considera- 
dos como mejor adaptados y más positivos, esto teniendo en cuenta que las puntuaciones no superaron valores moderados. El Plan Director del Turismo de la Región de Murcia es considerado el más conocido y el que más se adapta a los principios de la planificación estratégica, junto al Plan de Fomento del Turismo de la Región de Murcia. Este último es visto como el que cuenta con mayor grado de influencia positiva en la política turística y con un mayor grado de ejecución en el escenario turístico. Algo lógico, ya que el Plan Director de Turismo de la Región de Murcia, debido al cambio político y la crisis económica, no pudo ejecutarse.

En cuanto a la valoración del Área 3. Evaluación de los procesos clave de la planificación turística en la Región de Murcia respecto a los aspectos positivos y negativos del escenario turístico y los actores turísticos, se ha observado que, en general, los aspectos positivos han recibido menor consideración por parte de los expertos, siendo estos valorados con puntuaciones cercanas al valor central de la escala de valoración, mientras que los aspectos negativos les fueron asignadas puntuaciones en el rango de valores altos de la escala. Además, el consenso fue más reducido a la hora de valorar los aspectos negativos que los positivos, mostrando los expertos mayor divergencia de opinión respecto a estos últimos. De este modo, los expertos establecen un mayor consenso en los siguientes aspectos positivos de la planificación turística en relación al escenario regional: El plan aporta perspectiva y conocimiento integral del territorio (local y regional) en su vertiente turística y el ítem, Introduce las directrices sobre las que basar los desarrollos turísticos: calidad, sostenibilidad, innovación, excelencia, etc. Respecto de los actores regionales se indica mayor consenso en: Responde a la inquietud públicoprivada por el desarrollo del turismo regional. Por contra, el aspecto negativo de los procesos de la planificación turística en el escenario regional es: El plan no cuenta con la implantación de un proceso de revisión y actualización de objetivos y acciones, que garantice su eficiencia, respecto a los actores turísticos. El mayor consensuado, con un $65 \%$ respecto a los actores turísticos, es que: el plan no es publicado y no se difunde entre los agentes implicados. Estos tres ítems responden a las inquietudes y necesidades y, por lo tanto, puede dar cabida a nuevos criterios a considerar en la ejecución de la planificación estratégica del turismo.

En cuanto al Área 4. Análisis de las cuestiones fundamentales de la planificación turística e identificación de aspectos determinantes para su adecuación a la Región de Murcia, se ha visto que todos los factores clave propuestos han sido altamente valorados por los expertos, tanto en lo que se refiere al escenario y los actores turísticos regionales, como en los relativos a los indicadores genéricos de control de la implantación de los planes turísticos. Además, esta fue el área con mayor consenso. De este modo, se observa que respecto de las cuestiones fundamentales o claves de los procesos de la planificación turística en relación al escenario regional, los expertos consideran que: Deben desarrollarse por parte de la política turística regional instrumentos de planificación orientados a la mejora de la competitividad y con los mismos valores de consenso, del 65\%, que deben establecerse canales de Coordinación y colaboración con administración estatal y local, optimizando recursos y favoreciendo el marco de desarrollo de las acciones. Dan menor importancia al ítem que indica que la planificación debe tener un horizonte temporal de 10 años, algo que parece lógico si se determina que ningún plan regional ha alcanzado esta temporalidad. A este dato, le acompaña las referencias que se hacen respecto de la integración de los objetivos del plan a la de las demás políticas de desarrollo económico y a la participación de la población local en las acciones planificadas. 
Tabla 6

ÍTEMS CON MAYOR Y MENOR CONSENSO DEL ÁREA 3. EVALUACIÓN DE LOS PROCESOS CLAVE DE LA PLANIFICACIÓN TURISTIICA EN LAREGIÓN DE MURCIA

\begin{tabular}{|c|c|c|c|}
\hline \multicolumn{4}{|c|}{ ÁREA 3. Evaluación de los procesos clave de la planificación turística en la Región de Murcia } \\
\hline Ítem & Mediana & $\begin{array}{l}\text { Valor con } \\
\text { mayor \% }\end{array}$ & CV \\
\hline \multicolumn{4}{|c|}{$\begin{array}{l}\text { Ítem mayor consenso Bloque 3.1. Aspectos positivos de los procesos de la planificación turística } \\
\text { en relación al escenario regional }\end{array}$} \\
\hline $\begin{array}{l}\text { El plan aporta perspectiva y conocimiento integral del territorio } \\
\text { (local y regional) en su vertiente turística }(8.5)\end{array}$ & 5 & $5(35 \%)$ & 0.27 \\
\hline $\begin{array}{l}\text { Introduce las directrices sobre las que basar los desarrollos } \\
\text { turísticos: calidad, sostenibilidad, innovación, excelencia, etc. } \\
(8.10)\end{array}$ & 5 & $5(35 \%)$ & 0.27 \\
\hline
\end{tabular}

Ítem mayor consenso Bloque 3.2. Aspectos positivos de los procesos de la planificación turística en relación a los actores turísticos

\begin{tabular}{l|c|c|c}
\hline $\begin{array}{l}\text { Responde a la inquietud público-privada por el desarrollo del } \\
\text { turismo regional (8.13) }\end{array}$ & 4 & $4(41 \%)$ & 0.30 \\
\hline
\end{tabular}

Ítem mayor consenso Bloque 3.3. Aspectos negativos de los procesos de la planificación turística en relación al escenario regional

El plan no cuenta con la implantación de un proceso de revisión
$y$ actualización de objetivos y acciones, que garantice su
eficiencia (9.11)

Ítem mayor consenso Bloque 3.4. Aspectos negativos de los procesos de la planificación turística en relación a los actores turísticos

\begin{tabular}{l|l|l|l}
\hline $\begin{array}{l}\text { El plan no es publicitado y no se difunde entre los agentes } \\
\text { implicados }(9.18)\end{array}$ & 6 & $6(65 \%)$ & 0.16 \\
\hline
\end{tabular}

Ítem menor consenso Bloque 3.1. Aspectos positivos de los procesos de la planificación turística en relación al escenario regional

\begin{tabular}{l|c|c|c}
\hline $\begin{array}{l}\text { Se realiza de forma óptima desde la sostenibilidad ambiental y } \\
\text { preservación paisajistica }(8.7)\end{array}$ & 4 & $3(29 \%)$ & 0.43 \\
\hline
\end{tabular}

Ítem menor consenso Bloque 3.2. Aspectos positivos de los procesos de la planificación turística en relación a los actores turísticos

\begin{tabular}{l|l|l|l}
\hline $\begin{array}{l}\text { Propicia aceptación e identificación de la población local sobre } \\
\text { las acciones(8.16) }\end{array}$ & 4 & $4(35 \%)$ & 0.39 \\
\hline
\end{tabular}

Ítem menor consenso Bloque 3.3. Aspectos negativos de los procesos de la planificación turística en relación al escenario regional

\begin{tabular}{|c|c|c|c|}
\hline $\begin{array}{l}\text { A pesar de su carácter integrador, no tiene en cuenta otras } \\
\text { acciones de planificación, como la ordenación del territorio }(9.5)\end{array}$ & 6 & $\begin{array}{l}6(29 \%) \\
7(29 \%)\end{array}$ & 0.28 \\
\hline
\end{tabular}

Ítem menor consenso Bloque 3.4. Aspectos negativos de los procesos de la planificación turística en relación a los actores turísticos

\begin{tabular}{l|c|c|c}
\hline $\begin{array}{l}\text { Bajo nivel de implicación del sector privado y de la sociedad } \\
\text { en general (9.20) }\end{array}$ & 6 & $7(47 \%)$ & 0.25 \\
\hline
\end{tabular}

Fuente: elaboración propia. 
Respecto de los indicadores de evaluación, existe un mayor consenso en las referencias a la fijación de las metas y objetivos, indicando que estos deben ser concretos y cuantificables. Otro ítem con mayor consenso es el referente a la eficiencia esperada: presupuesto-resultado, aspecto de gran interés en la planificación estratégica del turismo regional.

Tabla 7

ITTEMS CON MAYOR Y MENOR CONSENSO DEL ÁREA 4. ANÁLISIS DE LAS CUESTIONES FUNDAMENTALES DE LA PLANIFICACIÓN TURISTICA E IDENTIFICACIÓN DE ASPECTOS DETERMINANTES PARA SU ADECUACIÓN A LA REGIÓN DE MURCIA

ÁREA 4. Análisis de las cuestiones fundamentales de la planificación turística e identificación de aspectos determinantes para su adecuación a la Región de Murcia

Ítem Mediana Valor con mayor \%

Ítem mayor consenso Bloque 4.1. Cuestiones fundamentales o claves de los procesos de la planificación turística en relación al escenario regional

Deben desarrollarse por parte de la política turística regional instrumentos de planificación orientados a la mejora de la competitividad (10.1)

7 $7(65 \%) \quad 0.07$

Ítem mayor consenso Bloque 4.2. Cuestiones fundamentales o claves de los procesos de la planificación turística en relación los actores turísticos

Coordinación y colaboración con administración estatal y local, optimizando recursos y favoreciendo el marco de desarrollo de las acciones (10.17) \begin{tabular}{l|l}
$7(65 \%)$ & 0.07
\end{tabular}

Ítem mayor consenso Bloque 4.3. Propuesta de indicadores genéricos que garanticen la implantación de la planificación

\begin{tabular}{l|l|l|l}
\hline Metas y objetivos concretos y cuantificables (11.2) & 6 & $7(47 \%)$ & 0.12 \\
\hline Eficiencia esperada: presupuesto-resultado (11.5) & 6 & $7(47 \%)$ & 0.12 \\
\hline
\end{tabular}

Ítem menor consenso Bloque 4.1. Cuestiones importantes de los procesos de la planificación turística en relación al escenario regional

\begin{tabular}{l|l|l|l}
\hline Debe tener un horizonte temporal de mínimo 10 años (10.2) & 6 & $6(41 \%)$ & 0.27 \\
\hline
\end{tabular}

Ítem menor consenso Bloque 4.2. Cuestiones importantes de los procesos de la planificación turística en relación los actores turísticos

\begin{tabular}{l|c|l|l}
\hline $\begin{array}{l}\text { Su resultado debe integrar los objetivos de las demás políticas de } \\
\text { desarrollo socioeconómico (10.15) }\end{array}$ & 6 & $\begin{array}{l}7(41 \%) \\
6(41 \%)\end{array}$ & 0.14 \\
\hline $\begin{array}{l}\text { Corresponsabilidad y participación de la población local (residente) } \\
\text { en las acciones (10.18) }\end{array}$ & 6 & $\begin{array}{l}7(35 \%) \\
5(35 \%)\end{array}$ & 0.14 \\
\hline
\end{tabular}

Ítem menor consenso Bloque 4.3. Propuesta de indicadores genéricos que garanticen la implantación de la planificación

\begin{tabular}{l|l|l|l}
\hline Determinar cuánto se quiere crecer $(11.3)$ & 6 & $6(47 \%)$ & 0.26 \\
\hline
\end{tabular}

Fuente: elaboración propia. 


\section{IV.2. Resultados del análisis cualitativo}

Los resultados del estudio llevado a cabo determinan un análisis global, donde se integran los resultados del análisis cuantitativo con las informaciones cualitativas obtenidas por los expertos y con las propias percepciones de los investigadores (Landeta, 1999). Así, además del análisis realizado por el cuestionario, estructurado a lo largo de las rondas, los participantes han aportado diversos comentarios de carácter cualitativo. Es evidente que esta información no se puede analizar estadísticamente, pero sí es necesario analizar las aportaciones, ya que enriquecen sustancialmente las conclusiones que se pueden extraer de la investigación. Dichas aportaciones son de naturaleza individual y responden a opiniones personales, por lo tanto, no quedan representados el conjunto de los integrantes de la investigación. Las aportaciones más significativas proceden de la primera ronda, pero como se verá, en la segunda ronda también se aportan aspectos de interés. Cabe recordar que se pretende, en todo momento, preservar la opinión de los expertos y así garantizar el máximo aprovechamiento del debate generado en todo el proceso. Por ello, se ha creído oportuno incluir un análisis cualitativo, incluyendo un espacio de texto libre en el cuestionario como "observaciones, observaciones o aportaciones de algún plan que sería importante destacar, Otras aportaciones que considere deban ser tenidas en cuenta en la investigación, para cada uno de los bloques. Una vez que la información ha sido transcrita y ordenada por bloques, se ha pasado a la siguiente fase que implica el reto de simplificar y ordenar, analizando el contenido, reconociendo patrones en los datos cualitativos y, así, obtener categorías significativas en el contenido (Fernández, 2006; Salgado, 2007).

Llevado a cabo un análisis de los contenidos, se observa que en la mayoría de los textos de opinión aportados por los expertos se establecen comentarios de reflexión y coincidencia respecto de la situación de la planificación estratégica regional. Respecto a la primera área de análisis, sobre la importancia y el grado de satisfacción de los instrumentos de la política turística, se vislumbra que la gestión de la marca es uno de los aspectos que representa mayor rechazo, ya que establece que existe una consecución de marcas que han motivado que la Región de Murcia no se identifique con ninguna en particular. Igualmente, se identifica la inexistencia de una planificación turística real y con continuidad en la región y, por lo tanto, no hay una relación entre la política turística y los contenidos de dichos planes; asimismo, expresan que cada cambio político ha elaborado un documento de planificación, que luego no ha tenido continuidad.

En la segunda de las aéreas, donde se evalúa el grado de conocimiento, la adaptación de los principios de planificación, la influencia y el grado de ejecución, se observan diferentes aportaciones relacionadas principalmente con el grado de desconocimiento de los planes de los actores turísticos, la falta de objetividad de los planes y la posible manipulación de los resultados por intereses políticos y la inexistencia de procesos de evaluación que determinen los resultados. Igualmente, se hace referencia a la escasa difusión del Documento Base para la Directrices Turísticas sostenibles de la Región de Murcia.

El área 3 del análisis establece que uno de los aspectos positivos de la planificación debería haber sido la recuperación y conservación de los recursos en toda su clasificación. Respecto de las aportaciones que proponen de forma abierta para todas las áreas de análisis, indicar que se hace referencia al gran desconocimiento del sector por la administración, 
donde se demanda una mayor colaboración y participación entre el sector público y privado y determinan, nuevamente, la inexistencia en términos reales de los procesos de planificación en los últimos años. Otro aspecto de interés es la falta de indicadores que evalúen los resultados de las acciones y las políticas llevadas a cabo para así conocer la repercusión de éstas y su relación con los recursos materiales y humanos puestos a su disposición. Una de las aportaciones del grupo de los expertos que merece una atención especial es la reflexión que se hace sobre si las competencias en planificación realmente deben tenerlas la administración pública a escala regional. Se cree que esta percepción es debido al carácter segregado y a las condiciones limitantes de las administraciones públicas, por su falta coordinación o por su ciclo corto de mandato.

Respecto de la valoración de las líneas de opinión, en función de la procedencia de los expertos, indicar que las aportaciones del grupo correspondiente a la administración pública son mínimas, limitándose a un solo experto, que indica la importancia de planes realistas, implementados de forma conjunta y con revisiones también conjuntas.

Por el contrario, el grupo de expertos formado por el sector privado realizan aportaciones varias, relacionadas, principalmente, con la ausencia de planificación, el desconocimiento de la misma y el excesivo número de documentos que no han sido eficaces, así como con los cambios políticos (siendo del mismo grupo parlamentario), que han motivado la realización de nuevos planes y transformaciones significativas como la marca. Los dos primeros planes fueron los responsables de la constitución de nuevos productos turísticos en la Región, respecto de los que no se sabe nada porque no han tenido ninguna repercusión en el turismo. Quizás hace falta mayor esfuerzo y claridad para transmitir el valor y objetivos de estos planes. Por último, solicitan una mayor colaboración y exponen que la planificación ha sido inexistente en términos reales.

Igualmente, se indica que los cambios políticos han marcado un cambio radical en la planificación y que se ha producido una falta de uniformidad e integración entre un periodo y otro. Los planes no son del todo reales y los documentos desarrollados con la participación del sector han sido excesivamente ambiguos. Finalmente, ratifican que no ha habido planificación en la Región de Murcia, a pesar de los documentos desarrollados.

\section{CONCLUSIONES DE LOS RESULTADOS}

Las aportaciones de la aplicación del método Delphi, han mostrado la posición que la planificación estratégica del turismo ha tenido en la Región de Murcia como instrumento de la política turística. Igualmente, han contribuido a la identificación de los factores, positivos y negativos, que determinan la planificación estratégica regional aplicada al sector turístico. Estos factores o ítems se han definido desde la revisión de la literatura científica, que bien pueden ser considerados como referencia de ítems de evaluación sobre planificación estratégica del turismo a escala regional. Dichos ítems han permitido identificar las cuestiones fundamentales y determinantes sobre las que se basa la planificación turística a dicha escala.

Como síntesis de lo expuesto por los expertos, indicar que los instrumentos de la política turística son importantes en cada una de sus variables y que se debe mejorar considerablemente la gestión que se ha hecho de la marca turística de la Región de Murcia y la gestión del proceso de planificación estratégica. Asimismo, dicha planificación estratégica del turismo 
en la Región de Murcia, a pesar de los documentos existentes, no ha contribuido, en gran medida, en la toma de decisiones de la política turística regional y, por lo tanto, en el desarrollo y crecimiento del sector turístico. Igualmente indicar que, en la primera década de la política turística regional, se atiende a la intención de llevar cabo una gestión pública del turismo basado en la planificación. A diferencia de los últimos años, hasta el año 2013 que se ha llevado a cabo el estudio, en los que dicha intención, a pesar de existir documentos, no es apreciable. Se muestra, asimismo, como resultado que los expertos manifiestan los aspectos positivos de los procesos de la planificación estratégica aplicado al turismo y determinan que los planes deben contar con la implantación de procesos de revisión actualizados, que garanticen su eficiencia, así como la importancia de ser documentos publicados y difundidos entre todos los agentes. Igualmente, es importante la implicación del sector privado, la sociedad en general, universidades y las propias administraciones en los procesos de planificación. Los factores determinantes en la planificación estratégica regional deben desarrollar instrumentos, que ayuden a la mejora de la competitividad; deben establecer una coordinación pública compartimentando las competencias y optimizando recursos y deben definir unos indicadores de evaluación sobre la base de los objetivos propuestos, resultados y costes. Por último, la planificación debe ser real y con una visión a largo plazo, integradora y con continuidad en el tiempo, por lo tanto, el plan debe establecer por sí mismo mecanismos de consenso y pactos sociales entre los distintos agentes.

Dicho todo esto, cabe indicar que las cuestiones que se consideran como fundamentales en la planificación turística, así como la identificación de aspectos determinantes para su adecuación a la Región de Murcia deben desarrollarse, por parte de la política turística regional, con instrumentos de planificación estratégica orientados a la mejora de la competitividad. De igual modo, es importante establecer canales de coordinación y colaboración con las administraciones estatal y local, optimizando recursos y favoreciendo el marco de las acciones.

De este modo, queda patente que a la planificación estratégica se le otorga una gran importancia por ser una herramienta necesaria para el desarrollo del turismo a escala regional, por su carácter integrador y por ser un documento de argumentación, que ordena al resto de instrumentos y decisiones de la política turística regional. Entre deficiencias en el proceso de planificación aparece la ausencia de procesos claros de implantación, revisión y actualización, que garanticen su eficiencia, respecto de los actores turísticos y la no presencia de canales de comunicación y difusión entre los agentes implicados con el objetivo de conocer las acciones a realizar.

No obstante, en la Región de Murcia, se percibe la inexistencia de una planificación turística real, ya que no hay una relación entre las políticas llevadas a cabo y lo expuesto en los planes. Este hecho conduce a la reflexión sobre si la administración pública, por su compartimentación de competencias, sus condiciones limitantes en el establecimiento de la coordinación y los cambios en las estructuras organizativas, debería reorganizarse en torno a un órgano de coordinación de ámbito regional interadministrativo más estable.

Si bien es cierto que la política turística, tras la crisis económica, ha adquirido una posición ventajosa al convertirse en elemento esencial en la diversificación productiva de las economías, a distintas escalas. Este nuevo lugar debe ayudar a posicionar y romper las barreras que impiden a la política turística ser considerada como una política de interés para la sociedad y para el propio territorio. 
Los instrumentos de la política turística son de diversa índole, aunque presenta una estructura fija: organizativos, normativos, financieros y otra variable orientada a la realización de programas específicos. La planificación estratégica ordena e integra cada una de estas estructuras y por su proceso de configuración otorga veracidad a la gestión pública del turismo. No obstante, solo si la planificación estratégica a escala regional se reposiciona en este ámbito de ordenación tendrá la posibilidad de participar de forma activa en la planificación territorial y urbana de los territorios turísticos.

Previo a este nuevo posicionamiento, es necesario establecer una revisión de su proceso de configuración poniendo énfasis en la fase que define el proceso de evaluación. De este modo, se debe hablar de un nuevo modelo de planificación que se base, por un lado, en la diversificación de documentos y, por otro, en los paradigmas de la nueva gestión asentada en la información, innovación, participación e integración territorial.

La Región de Murcia debe revisar sus políticas turísticas, reflexionar sobre el modelo turístico sobre el que quiere basar su crecimiento, adecuar la gestión de la marca turística, revisar de forma integral las oportunidades territoriales

La administración pública debe activar estrategias que respondan, de forma dinámica, a las inquietudes del tejido empresarial, que ha de estar, a su vez, en el mismo entorno de participación. Es esencial compartir responsabilidades y compromisos, e igualmente es determinante una gestión inteligente de los recursos. Para ello, se debe establecer un marco de planificación estratégica a escala regional con factores clave, y debidamente consensuado, que aporte nuevas oportunidades, generado un verdadero contexto territorial turístico en un futuro inmediato para la Región de Murcia.

\section{BIBLIOGRAFIA}

ANDRÉS, J.L. (1998): Turismo y Territorio en la Región de Murcia. Murcia. Instituto de Fomento de Región de Murcia.

ANDRÉS, J.L. (1999): «Turismo y Estrategias para la Recuperación de las ciudades históricas». Cuadernos de Turismo, $\mathrm{n}^{\circ} 3$, pp. 7-30.

ANDRÉS, J.L. (2004): «Incertidumbres en el espacio agrícola y proceso urbanizador «resort» en la Región de Murcia», Cuadernos de Turismo, n 14, pp. 7-65.

ANDRÉS, J.L. y ESPEJO, C. (2006): «Interacción mito religioso/producto turístico en la imagen de la ciudad: Caravaca de la Cruz (Murcia)», Cuadernos de Turismo, n ${ }^{\circ}$ 18, 7-61. ANDRÉS, J.L. (1999): "Región de Murcia”. En Bote, V. (Dir.). La Actividad Turística Española en 1998. Asociación Española de Expertos Científicos en Turismo. Madrid, (AECIT), 399-426.

ANDRÉS SARASA, J.L. (1999b): “Turismo y Estrategias para la Recuperación de las ciudades históricas". Cuadernos de Turismo, $\mathrm{n}^{\circ}$ 3, 7-30.

ANTÓN, S. y GONZÁLEZ, F. (Coords.) (2005): Planificación territorial del turismo. Barcelona. Editorial UOC.

BAÑON y MARTÍNEZ, R. (2003): La evaluación de la acción y de las políticas públicas. Madrid. Díaz Santos.

BARROSO, M. y FLORES, D. (2007): «La política turística como parte de la política económica» Análisis Turístico, $\mathrm{n}^{\circ}$ 4. 5-21. 
BAYÓN, F. (Dir.) (1999): 50 años del Turismo Español. Un análisis histórico y estructural. Madrid. Centro de Estudios Ramón Areces S.A. Escuela Oficial de Turismo.

BEAS, L. (2009): «Los Planes de Excelencia turística como objeto de estudio. Una propuesta metodológica d evaluación». Estudios de Turismo, nº 182, 31-52.

BEAS, L. (2012): «Los Planes de Excelencia Turística en España (1992-2006). Una opuesta por la revitalización de los destinos. Revisión de su implantación e impactos». Scripta Nova. Vol. XVI, 411.

BENGOECHEA, A. (2009): «Hacía una política turística en Europa: directrices y tendencias recientes». Revista de Análisis Turístico, $\mathrm{n}^{\circ}$ 7, 5-21.

BOTE, V. y MARCHENA, M. (1996): "Política Turística”. En Pedreño, A. (Dir.) y Monfort Mir, V. (Coord.): Introducción a la Economía del turismo en España. Madrid. Editorial Civitas.

CALS, J. (1974): Turismo y política turística en España; una aproximación. Barcelona. Editorial Ariel.

CEBRIÁN, A. (2004): «Políticas institucionales y turismo cultural. El ejemplo de la Comunidad de Murcia». Cuadernos de Turismo, $\mathrm{n}^{\circ}$ 13, 7-25.

CEBRIÁN, A. (2005). «Acción local, turismo y patrimonio en la Comunidad de Murcia». Cuadernos de Turismo, $\mathrm{n}^{\mathrm{o}} 16,65-83$.

DALKEY, N. y HELMER, O. (1963): «An experimental application of the Delphi method to the use of experts». Management Science, vol. 9, n 3, 458-467.

DELBEQ, A., VAN DE VEN, A. y GUSTAFSON, D.H. (1975): Group techniques for program planning: A guide to nominal group and Delphi processes. Glenview, USA: Scott, Foresman and Company.

DÍAZ, F.M. (Coord.) (2006): Política turística: la competitividad y sostenibilidad de los destinos. Valencia. Tirant Lo Blanch.

FAYÓS-SOLÁ, E. (2004): «Política turística en la era de la globalización». Mediterráneo Económico. n $5,215-235$.

FERNÁNDEZ, L. (2006): ¿Cómo analizar datos cualitativos?. Butllertí La Recerca, 1-13, Institut de Ciéncies de 1’Eduación. Universitat de Barcelona. http://www.ub.edu/ice/ recerca/pdf/ficha7-cast.pdf . Consulta 1 de abril de 2014.

FIGUEROLA, M. (1999): Introducción al estudio económico del turismo. Madrid. Civitas.

FIGUEROLA, M. (2004): «La organización técnica y administrativa de la política económica del turismo. Especial referencia al caso español». Quaderns de Política Económica, $\mathrm{n}^{\circ}$ 7, 9-34.

GARCÍA, R., ANDRÉS, J.L. y ESPEJO, C. (2016). «Conocimientos tácitos, transversalidad turística y desarrollo local. El ejemplo de una ciudad desolada y en proceso de reconversión: Lorca (Región de Murcia, España)». Pasos. Revista de Turismo y Patrimonio Cultural, vol. 14, n ${ }^{\circ}$, 1.093-1.107.

GÓMEZ, B., LÓPEZ, F., CORS, M. (2004). «Turismo y planificación estratégica: El estudio e informe estratégico del turismo urbano y territorial». Cuadernos Geográficos, $\mathrm{n}^{\circ}$ 34, 95-109.

GORDON, T.J. y HELMER, O. (1964): Report on a Long Range Forecasting Study. Santa Monica: The RAND Corporation.

HALL, C. M. y JENKINS, J.M. (1995): Tourism and Public Policy, Londres. Routledge. 
IVARS, J.A. (2003): Planificación turística de los espacios regionales en España. Generalitat Valenciana. Editorial Síntesis.

IVARS, J.A. (2006): “La política turística”. En SÁEZ, A.; MARTÍN, P. Y PULIDO, J.L. (Ed.): Estructura económica del turismo. Madrid, Síntesis 261-284.

KAYNAK, E. y MACAULAY, J.A. (1984): «The Delphi technique in the measurement of tourism market potential: the case of Nova Scotia». Tourism Management,vol. 5, $\mathrm{n}^{\circ} 2,87-101$.

KIBEDI, G. (1981): «Future Trends in international tourism». Revue de Tourism, vol. 36, $\mathrm{n}^{\circ}$ $1,3-6$.

LANDETA, J. (1999): El método Delphi: una técnica de previsión para la incertidumbre. Barcelona: Ariel.

LANDETA, J. (2006): «Current validity of the Delphi method in social sciences». Technological forecasting and social change, vol.73, $\mathrm{n}^{\circ} 5,467-482$.

LANDETA, J., MATEY, J., RUIZ, V. y VILLARREAL, O. (2002): «Alimentación de modelos cuantitativos con información subjetiva: aplicación Delphi en la elaboración de un modelo de imputación del gasto turístico individual en Catalunya». QÜESTIIÓ, n 26 , 175-196.

LEE, C. F. Y KING, B. E. (2008): «Using the Delphi method to assess the potential of Taiwan $>$ s hot springs tourism sector». International Journal of Tourism Research, vol.10, $\mathrm{n}^{\mathrm{o}} 4,341-352$.

LÓPEZ OLIVARES, D., ANTÓN, S., NAVARRO, E., PERELLI, O., SASTRE, F. (2005): «Cambios y transforamaciones en el actual modelo turístico de España», Annals of Tourism Research en Español, vol.7, 423-446

LÓPEZ PALOMEQUE, F. (1999): «Política turística y territorio en el escenario de cambio turístico». Boletín de la Asociación de Geógrafos Españoles, n ${ }^{\circ} 28,23-38$.

LÓPEZ PALOMEQUE, F. (2004): «La gestión pública del turismo en la Cataluña. Organización y política turística de la administración autonómica». Investigaciones Geográficas, $\mathrm{n}^{\mathrm{o}} 34,5-27$.

MILLÁN, M. (1999): «El turismo rural en la planificación económica de la Región de Murcia». Cuadernos de Turismo, ${ }^{\circ}$ 4, 51-72.

MILLER, G. (2001): «The development of indicators for sustainable tourism: results of a Delphi survey of tourism researchers». Tourism Management, vol. 22, nº 4, 351-362.

MONFORT, V.M., (2000): «La política turística: una aproximación». Cuadernos de Turismo, $\mathrm{n}^{\mathrm{o}} 6,7-27$.

MOUTHINO, L. y WITT, S.F. (1995): «Forecasting the tourism environment using a consensus approach». Journal of Travel Research, vol. 33, n 4, 45-60.

OKOLI, C. y PAWLOWSKI, S. D. (2004): «The Delphi method as a research tool: an example, design considerations and applications». Information \& Management, vol. 42, $\mathrm{n}^{\circ} 1$, $15-29$.

ORTEGA, F. (2008): «El método Delphi, prospectiva en Ciencias Sociales a través del análisis de un caso práctico». Revista EAN, $\mathrm{n}^{\circ}$ 64, 31-54.

PEDROÑO y MONFORT, V.M. (Cood.) (1996): Introducción a la Economía del turismo en España. Editorial Madrid. Civitas.

PULIDO, J.I. (2004): «Introducción. Referencias básicas para el análisis de la política turística en España». Quaderns de Política Económica. $2^{\circ}$ época, vol. 7, 1-8. 
PULIDO, J.I. (2007a): «El turismo en el desarrollo económico de los parques naturales andaluces. Un análisis Delphi de los principales déficit». Revista de Estudios Empresariales. Segunda época, $\mathrm{n}^{\circ} 1,110-137$.

PULIDO, J.I. (2007b): «Elementos para orientar la formulación de una política turística sostenible en los parques naturales andaluces». Cuadernos de Turismo, n 19, 167-188.

ROWE, G. y WRIGHT, G. (2001): «Expert opinions in forecasting: the role of the Delphi technique». En Principles of forecasting, Springer, 125-144.

SALGADO, A. C. (2007): «Investigación cualitativa: diseño, evaluación del rigor metodológico y restos». Liberabit, vol. 13 nº13, 71-78.

SIMANCAS, M. (Coord.) (2016): La planificación y gestión territorial del turismo. Madrid. Ed. Síntesis.

SOLSONA, J. (2010): Desarrollo turístico en Espacio Rural. Análisis de una situación prospectiva. Estudio aplicado a la Comunitat Valenciana. Tesis Doctoral, Universitat Jaume I de Castellón, 704.

SOLSONA-MONZONÍS, J. y LÓPEZ OLIVARES, D. (2012): «Factores de Localización y desarrollo turístico en el espacio rural de la Comunidad Valenciana». Boletín de la Asociación de Geógrafos Españoles, n ${ }^{\circ}$ 59, 221-244.

TORRES BERNIER, E. (2004): «Del turismo en la política económica a la política económica del turismo». Quaderns de Política Económica. Revista electrónica $2^{\circ}$ época, vol.7, 49-71.

TSAUR, S.H., LIN, Y. C. y LIN, J.H. (2006): «Evaluating ecotourism sustainability from the integrated perspective of resource, community and tourism». Tourism management, vol. $27, \mathrm{n}^{\circ} 4,640-653$.

VALDÉS PÉLÁDEZ, L. (2004): «La política turística de la Unión Europa». Quaderns de Política Económica. Revista electrónica $2^{\circ}$ época, vol. 7, 114-134.

VELASCO, M. (2004): La política turística. Gobierno y Administraciones Turísticas en España (1952-2004). Valencia. Fundación Cañada Blanch y Ayuntamiento de Burriana.

VELASCO, M. (2005): «¿Existe la política turística? La acción pública en materia turística». Política y Sociedad, vol. 42, nº1, 169-195.

VELASCO, M. (2011): «La política turística. Una arena de acción autonómica». Cuadernos de Turismo, $\mathrm{n}^{\circ} 27,953-969$.

VELASCO, M. (2016): «Entre el poder y la racionalidad: gobierno del turismo, política turística, planificación turística y gestión pública del turismo». Pasos. Revista de Turismo y Patrimonio Cultural vol. 14, n⿳3 3, 577-594.

VERA, J.F. y ESPEJO, C. (2006): "El papel de los instrumentos de planificación en las dinámicas productivas y territoriales: las directrices y el Plan de Ordenación del Litoral de la Región de Murcia". En Gobernanza territorial en España. Claroscuros de un proceso a partir del estudio de casos. Valencia. Universitat de València.

VERA, J.F. y MARCHENA, M. (1996): “El modelo turístico español: perspectivas económica y territorial”. En PEDREÑO, A. (Dir.) y MONFORT, V. M. (coord.): Introducción a la Economía del turismo en España. Editorial Civitas. Madrid.

YOUNG, Y.W., KENG, K.A. y LENG, T.L. (1989). «A Delphi forecast for the Singapore tourism industry: future scenario and marketing implications». International Marketing Review, vol. 6, n $3,35-46$. 